\title{
Immune parameters associated with survival in metaplastic breast cancer
}

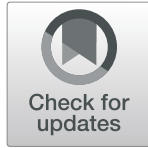

Xue Chao ${ }^{1,2+} \mathbb{D}$, Lili Liu ${ }^{1,2+}$, Peng Sun ${ }^{1,2}$, Xia Yang ${ }^{1,2}$, Mei Li ${ }^{1,2}$, Rongzhen Luo ${ }^{1,2}$, Yuhua Huang ${ }^{1,2}$, Jiehua He ${ }^{1,2}$ and Jingping Yun ${ }^{1,2^{*}}$

\begin{abstract}
Background: Metaplastic breast carcinoma (MBC) is a rare histological type of breast cancer, which commonly shows resistance to standard therapies and is associated with poor prognosis. The immune microenvironment in $\mathrm{MBC}$ and its significance has not been well established due to its low incurrence rate and complex components. We aimed to investigate the diversity of immune parameters including subsets of TILS and PDL1/PD1 expression in MBC, as well as its correlation with prognosis.
\end{abstract}

Methods: A total of 60 patients diagnosed with MBC from January 2006 to December 2017 were included in our study. The percentage (\%) and quantification (per $\mathrm{mm}^{2}$ ) of TILs and presence of tertiary lymphoid structures (TLS) were evaluated by hematoxylin and eosin staining (HE). The quantification of CD4+, CD8+ TILs (per mm²), and PD1/PDL1 expression were evaluated through immunohistochemistry and analyzed in relation to clinicopathological characteristics. A $\geq 1 \%$ membranous or cytoplasmatic expression of PD1 and PDL1 was considered a positive expression.

Results: We found squamous cell carcinoma MBC (33/60, 55\%) exhibiting most TILs of all the MBC subtypes ( $p=$ 0.043). Thirty-three of 60 (50\%) of the patients had coexisting invasive ductal carcinoma of no special type (IDCNST), and the average percentage of TILs in MBC components was lower compared with NST components ( $p<$ 0.001). Thirty (50\%) patients exhibited positive ( $\geq 1 \%)$ PDL1 expression in their tumor cells, while $36(60 \%)$ had positive ( $\geq 1 \%)$ PDL1 expression in their TILs. Twenty-seven (45\%) of all the patients had positive ( $\geq 1 \%)$ PD1 expression in their tumor cells and $33(55 \%)$ had PD1-positive ( $\geq 1 \%)$ stromal TILs. More CD8+ TILs were associated with positive PDL1 expression of tumor cells as well as positive PD1 expression in stromal cells. Greater number of stromal TILS $\left(>300 / \mathrm{mm}^{2}, 20 \%\right)$, CD4+ TILS $\left(>250 / \mathrm{mm}^{2}\right)$, and CD8+ TILs $\left(>70 / \mathrm{mm}^{2}\right)$ in MBC were found associated with longer disease-free survival. Positive expression of PDL1 in tumor cells ( $\geq 1 \%)$ and PD1 in stromal cells $(\geq 1 \%)$ were also associated with longer survival.

Conclusions: The immune characteristics differ in various subtypes as well as components of MBC. Immune parameters are key predictive factors of $\mathrm{MBC}$ and provide the clinical significance of applying immune checkpoint therapies in patients with MBC.

Keywords: Metaplastic breast cancer, Immune characteristics, Prognosis

\footnotetext{
* Correspondence: yunjp@sysucc.org.cn

${ }^{+}$Xue Chao and Lili Liu contributed equally to this work.

'Sun Yat-sen University Cancer Center, State Key Laboratory of Oncology in

South China, Collaborative Innovation Center for Cancer Medicine,

Guangzhou, People's Republic of China

${ }^{2}$ Department of Pathology, Sun Yat-sen University Cancer Center, 651

Dongfeng East Road, Guangzhou 510120, People's Republic of China
}

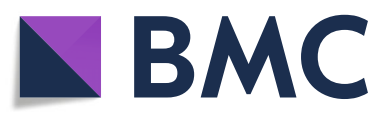

() The Author(s). 2020 Open Access This article is licensed under a Creative Commons Attribution 4.0 International License, which permits use, sharing, adaptation, distribution and reproduction in any medium or format, as long as you give appropriate credit to the original author(s) and the source, provide a link to the Creative Commons licence, and indicate if changes were made. The images or other third party material in this article are included in the article's Creative Commons licence, unless indicated otherwise in a credit line to the material. If material is not included in the article's Creative Commons licence and your intended use is not permitted by statutory regulation or exceeds the permitted use, you will need to obtain permission directly from the copyright holder. To view a copy of this licence, visit http://creativecommons.org/licenses/by/4.0/. The Creative Commons Public Domain Dedication waiver (http://creativecommons.org/publicdomain/zero/1.0/) applies to the data made available in this article, unless otherwise stated in a credit line to the data. 


\section{Background}

Metaplastic breast carcinoma (MBC) is a rare subtype of invasive breast carcinoma, which accounts for approximately $1 \%$ of all breast malignancies [1]. MBC displays various histological subtypes, exhibiting metaplastic change from neoplastic epithelium to squamous cells and/or mesenchymal elements. MBC usually lacks the expression of hormone receptor and HER2 and is considered as a subtype of triple-negative breast cancer (TNBC). Previous studies have shown that MBC is less sensitive to adjuvant therapy $[2,3]$ and has poorer prognosis compared with invasive ductal carcinoma in the same clinical stage $[4,5]$, including the TNBC [6].

Tumor-infiltrated lymphocytes (TILs) are mononuclear lymphocytes present in the tumoral tissue, reflect an immune response in the tumor microenvironment, and can be easily identified in formalin-fixed paraffin-embedded tissues. Increased TILs in tumors were found to be associated with better prognosis and an increase in systematic therapy sensitivity in TNBC [7-9]. The subsets of TILs were also shown to be a prognostic factor for TNBC $[10,11]$. The dynamic expression of programmed cell death ligand 1 (PDL1) and PD1 on both the tumor and immune cells can either disrupt or sustain tumor growth, which is correlated with prognosis in breast cancer [12-14]. Furthermore, the TILs and PDL1/PD1 expression were both predictors of effectiveness of immune checkpoints therapy in breast cancer $[15,16]$ and TILs were shown to be correlating with PDL1/PD1 expression [17].

Data involving the immune microenvironment of $\mathrm{MBC}$ is limited and short of quantification. Given the heterogeneous components of $\mathrm{MBC}$ and the prognostic significance of TILs and its subsets as well as PDL1/PD1 expression in breast cancer, we investigated the expression of PD1/PDL1 and quantified TILs to determine their association with clinicopathological features and survival outcome in a cohort of MBC.

\section{Methods}

\section{Patients and samples}

This study was conducted using the data of patients diagnosed with MBC from January 2006 to December 2017, treated at the Sun Yat-sen University Cancer Center. All patients diagnosed with $\mathrm{MBC}$ were reviewed. Patients with recurrences at diagnosis, previous malignancies, and immune deficiencies were excluded. The clinical parameters investigated were age, pathological diagnosis, symptoms, present history, past history, image examination including ultrasound, and mammography results, operative records, and adjuvant therapy data were extracted from the original medical records. The follow-up information was gained from medical records and telephonic interviews. The primary endpoint of the study was disease-free survival. The protocol of this study was approved by the institutional Ethics Committee of Sun Yat-sen University Cancer Center, and consent for the use of data in research was obtained from each participant.

\section{Pathological assessment}

The pathological categories of $\mathrm{MBC}$ were considered based on the WHO classification [18]. The subtypes included low-grade fibromatosis-like carcinoma, squamous cell carcinoma, spindle cell carcinoma, and carcinoma with mesenchymal differentiation (chondroid, osseous, and other mesenchymal differentiation). A mixed type $\mathrm{MBC}$ was considered when 2 or more subtypes of MBC were present on the histological slides. All the original tumor slides of each patient were reviewed by 2 pathologists. The hormone receptor and HER2 receptor status were extracted from the original pathological reports.

\section{Evaluation of TILs}

TILs were evaluated on the hematoxylin and eosin (H\&E) sections of the tumor following the guidelines of the international TILs working group [19]. The TILs were evaluated within the invasive border and a percentage, as well as a quantification of TILs in square millimeter, was given. An average percentage and quantification of TILs were documented for each case. For mixed type or MBC with invasive ductal carcinoma of no-special type (IDC-NST), the TILs percentage was evaluated in different components, while the TILs quantification was counted as an average number. The stromal TILs were analyzed for the epithelial tumor component. For cases with mesenchymal compartment, the TILs in the epithelium were called intra-epithelium TILs, while the TILs analyzed within the mesenchymal element were called mesenchymal TILs. Tertiary lymphoid structure (TLS), aggregates that recapitulate the components and architecture of a lymph node, was also evaluated as previously described $[19,20]$. Dual staining of CD3/CD20 was also performed to validate the TLS number according to Buisseret's study [21]. Furthermore, the quantification of TILs was performed manually through the digital scan using the Aperio imagescope (Leica Biosystems). Two pathologists evaluated all the data above separately and blind to the clinical outcomes. Consensus was reached between the two authors if there was a discrepancy among the collected data.

\section{Immunohistochemical evaluations}

Formalin-fixed paraffin-embedded (FFPE) tissue sections were stained for PD-L1 (clone: antihuman PD-L1 rabbit monoclonal antibody E1L3N, Cell Signaling Technology), PD-1 (Clone UMAB199, ZSGB-Bio), CD4 (Clone 
EP204, ZSGB-Bio), CD8 (Clone SP16, ZSGB-Bio), and CD68 (Clone PG-M1, ZSGB-Bio). Dual CD3/CD20 immunohistochemical stain was performed as Buisseret et al. [21] (Supplemental Figure 1). A $\geq 1 \%$ membranous or cytoplasmatic expression of PD1 and PDL1 in tumor cells was considered positive expression. An immune cell was considered "PD-L1/PD-1 positive" if it featured any PD-L1 staining due to the small size of the lymphocytes. The percentage of PD-L1-positive tumor cells was proportionally evaluated in all tumor cells. PD-1 and PD-L1 immune cells were assessed relative to the whole tumor area, and as previously described [14, 22]. Quantification of CD4 and CD8 positive TILs were performed with digital imaging analysis (Halo imaging analysis software; Indica Labs, Corrales, NM) as well as manually. We manually annotated the system to indicate different components of $\mathrm{MBC}$ including epithelial area, mesenchymal area, and the stromal area. The software counted the number of positive immune cells in the tumor areas of the whole slides while the two pathologists counted the positive immune cells through the digital scan of the slides separately. Consensus was reached between the two authors if there was a discrepancy among the collected data.

\section{Statistics}

Categorical variables were grouped based on the clinical findings, and decisions on the groups were made before modeling. The results were compared using the $\chi^{2}$ test or Fisher's exact test. Continuous variables were compared using the $t$ test. Comparison of TILs parameters between different groups used Wilcoxon test due to the limited sample size. Spearman's rank correlation tests were used to assess the associations among infiltrations of CD4+, CD8+TILs, and PD-L1+ tumor/immune cells. The median of the CD4+, CD8+, and overall TILs counts is used as a cut-off value. Cox regression models were used to examine the prognostic effect of each variable. Kaplan-Meier curves were used to compare subgroups defined by biomarkers. A $p$ value $<0.05$ was considered statistically significant. All statistical analyses were carried out using the SPSS software, version 25.0 (IBM Corp, 1987, Chicago, USA), and GraphPad Prism 8 (GraphPad software, Inc.).

\section{Results}

\section{Clinicopathological characteristics}

A total of 60 surgically resected FFPE MBC samples were assessed in our study. The median age at diagnosis was 50 years (range, 25-81 years). The clinicopathological characteristics are listed in Table 1 . Of all the 60 MBC patients, 33 were diagnosed as squamous cell carcinoma, 4 as spindle cell carcinoma, 8 as mesenchymal
Table 1 Clinicopathological characteristics

\begin{tabular}{|c|c|c|}
\hline Patients characteristics & $n$ & $\%$ \\
\hline Age (median/range) & $50 / 25-81$ & \\
\hline \multicolumn{3}{|l|}{ Histological subtype } \\
\hline Squamous cell carcinoma & 33 & 55.0 \\
\hline Spindle cell carcinoma & 4 & 6.56 \\
\hline Chondriod differentiation & 4 & 6.56 \\
\hline Osseous differentiation & 4 & 6.56 \\
\hline Fibromatosis-like & 2 & 3.28 \\
\hline Mixed type & 13 & 21.67 \\
\hline With invasive carcinoma (no special type) & 33 & 55.0 \\
\hline \multicolumn{3}{|l|}{ Tumor size(mm) } \\
\hline $0-20$ & 10 & 16.67 \\
\hline $21-50$ & 33 & 55 \\
\hline$>50$ & 17 & 28.33 \\
\hline \multicolumn{3}{|l|}{ Lymph node metastasis } \\
\hline Negative & 41 & 68.33 \\
\hline $1-3$ & 17 & 28.33 \\
\hline $4-10$ & 2 & 3.33 \\
\hline$>10$ & 0 & - \\
\hline \multicolumn{3}{|l|}{ Lymphovascular invasion } \\
\hline Present & 16 & 26.7 \\
\hline Absent & 41 & 68.3 \\
\hline Unknown & 3 & 5 \\
\hline \multicolumn{3}{|l|}{ Surgery type } \\
\hline Breast-conserving surgery & 7 & 11.67 \\
\hline Mastectomy & 53 & 88.67 \\
\hline \multicolumn{3}{|l|}{ Systematic therapy } \\
\hline Chemotherapy* & 56 & 93.33 \\
\hline Radiotherapy & 52 & 86.67 \\
\hline \multicolumn{3}{|l|}{ Clinical outcome } \\
\hline Local recurrences & 5 & 8.02 \\
\hline Distant metastasis & 7 & 11.48 \\
\hline Total death & 6 & 9.81 \\
\hline Cancer-specific death & 3 & 4.92 \\
\hline
\end{tabular}

*4/56 patients had neoadjuvant chemotherapy

differentiation, 2 as fibromatosis-like, and 13 as mixed type.

A mixed MBC was defined as two or more metaplastic components. For the 13 mixed MBCs, 4/13 were mixed with squamous cell carcinoma and chondroid/chondroid matrix production; $6 / 13$ were mixed with squamous cell carcinoma, spindle cell type, and invasive carcinoma with no special type; and 3/13 were mixed with squamous cell carcinoma and spindle cell type.

Thirty-three of 60 of the patients had coexisting IDCNST. Twenty-eight of 33 of these tumors were triple- 
negative while 5/33 were hormone receptor-positive. Additional details are listed in Supplemental Table 1.

\section{Immune characteristics of different subtypes of MBC}

For pure carcinoma, the TILs mainly located in stroma around the carcinoma nests. While for MBC with mesenchymal components, the TILs infiltrated diffuse around the mesenchymal cells. MBC with different mesenchymal elements were displayed in Fig. 1.

For each case, an average number of total TILs as well as CD4+ and CD8+ TILs, the percentage of TILs of each component, and the percentage of positive PD1 and PDL1 expression in both tumor cells and TIL was evaluated. Figure 2 showed a mixed type MBC composed of both squamous cell cancer and chondroid matrix and its expression of different immune parameters (CD4, CD8, PDL1, and PD1). The staining of CD68 in the same case was displayed in Supplemental Figure 2.

Of all subtypes of $\mathrm{MBC}$, the squamous cell carcinoma MBC exhibited the greatest number of TILs. The squamous cell carcinoma MBCs were more likely to have > $300 / \mathrm{mm}^{2}$ (median) TILs compared to other subtypes $(p=0.043)$. None of this tendency was observed in CD4+ and CD8+ TILs. Neither does the CD4/CD8 ratio nor the CD68 positive cells displayed difference among MBC subtypes (Fig. 3 and Supplemental Figure 3).
For different components of $\mathrm{MBC}$, a comparison of TILs in percentage is shown in Fig. 4a. Of all the 5 components, squamous cells showed the most number of TILs $(p<0.001)$. For the 33 MBCs with IDC-NST, the average percentage of TILs in MBC components was lower in the IDC-NST components (Fig. $4 \mathrm{~b}, p<0.001$ ). There is no difference in TILs percentage between simple MBC (27 cases) and MBC combined with IDC-NST $(p=0.25)$.

Thirty (50\%) patients exhibited positive PDL1 expression in their tumor cells, while $36(60 \%)$ had positive PDL1 expression in their TILs. Twenty-four (40\%) patients had positive PDL1 expression in both tumor cells and TILs. Eighteen (30\%) patients exhibited negative PDL1 in neither tumor cells nor TILs. Six (10\%) patients had positive expression in tumor cells and negative expression in TILs. Twelve (20\%) patients had positive expression in TILs and negative expression in tumor cells. Twenty-seven (45\%) of all the patients had positive PD1 expression in their tumor cells and $24(40 \%)$ had PD1 positive stromal TILs. The correlation of PDL1/PD1 expression in tumor cells and TILs were listed in Supplemental Table $2 \& 3$. There was no significant association of PDL1/PD1 expression between different MBC subtypes (Supplemental Table 4).

Among all the immune parameters, a higher level of CD8+ TILs was found to be correlated with positive
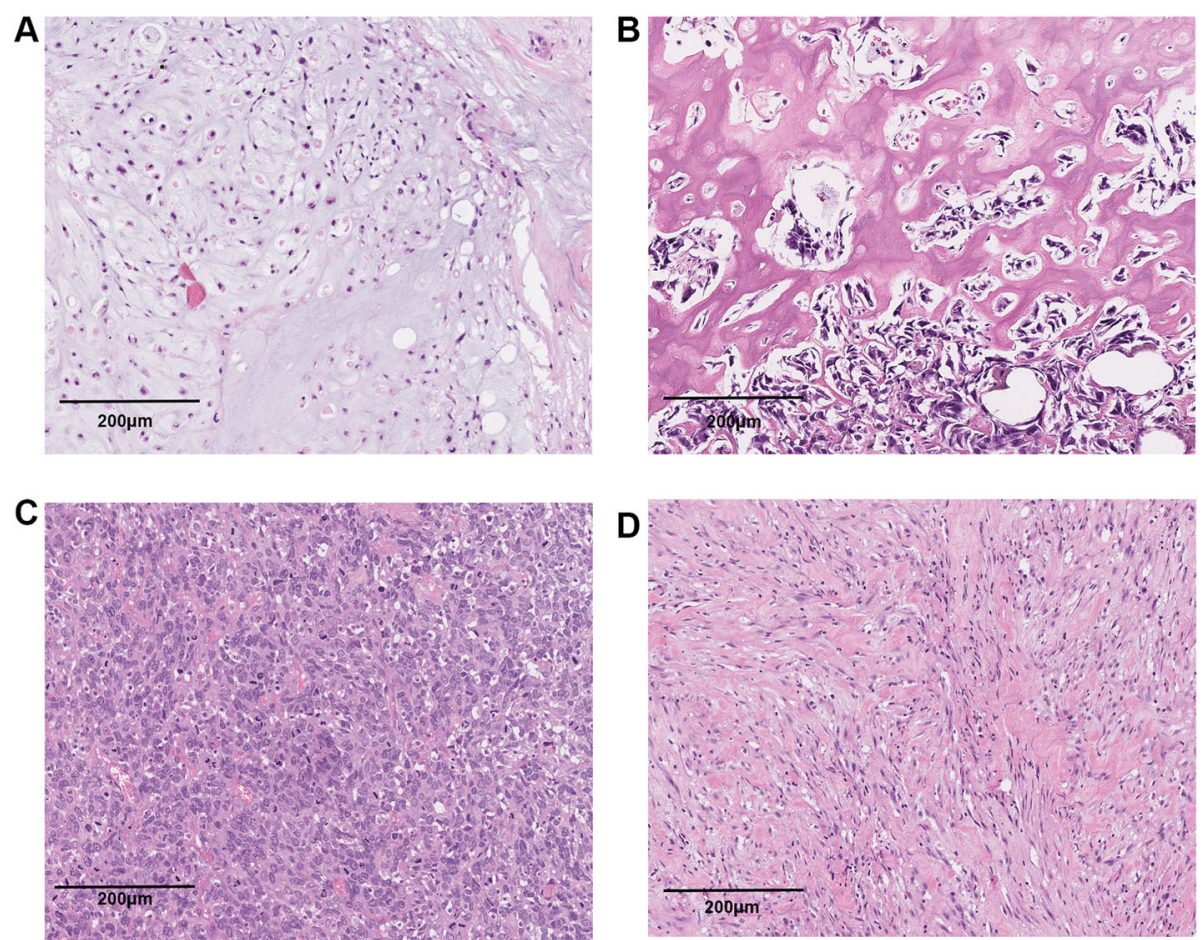

Fig. 1 Hematoxylin and eosin-stained section of MBC with mesenchymal elements and the distribution patterns of TILs. a Chondroid differentiation. b Osseous differentiation. c Spindle cell. d Fibromotosis-like 

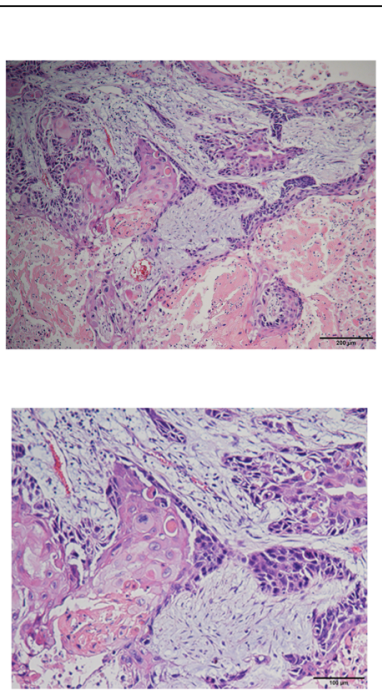

Fig. 2 Representative hematoxylin and eosin-stained section of a mixed type MBC (squamous cell cancer component and chondroid-matrix component) with corresponding CD4, CD8, PDL1, and PD1 stains (original magnification $\times 200$ )

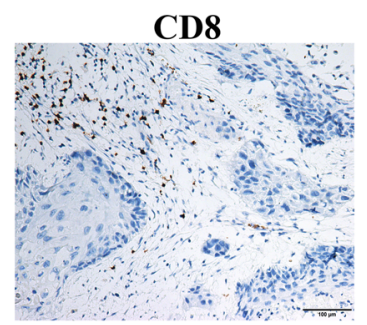

PD-1

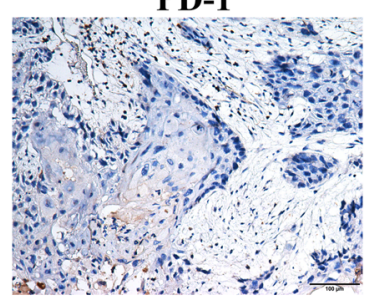

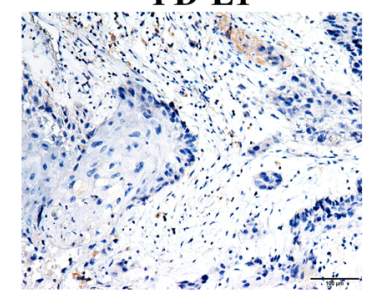

PD-L1

\section{(0)}

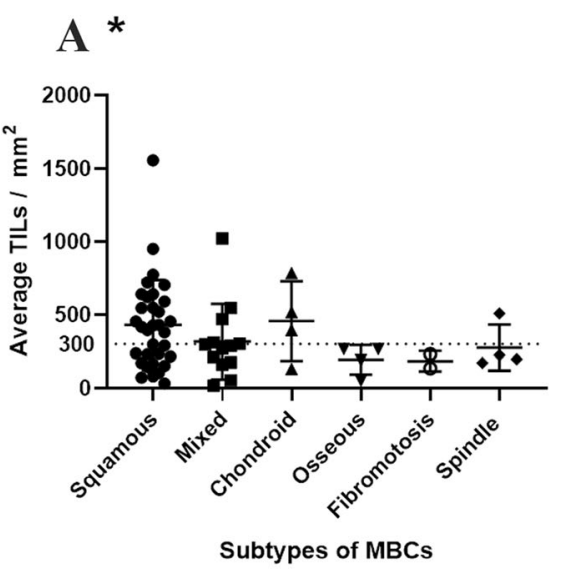

C

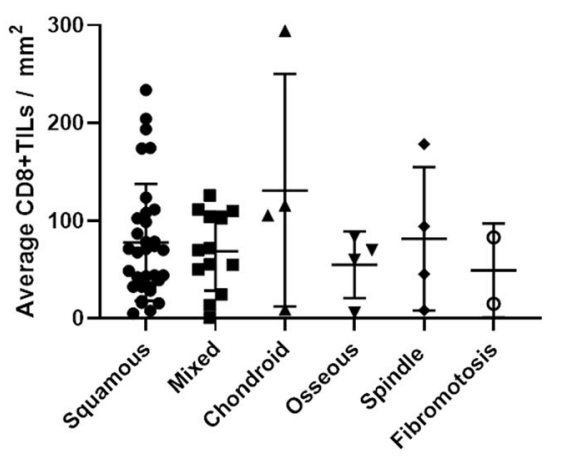

Subtypes of MBCs
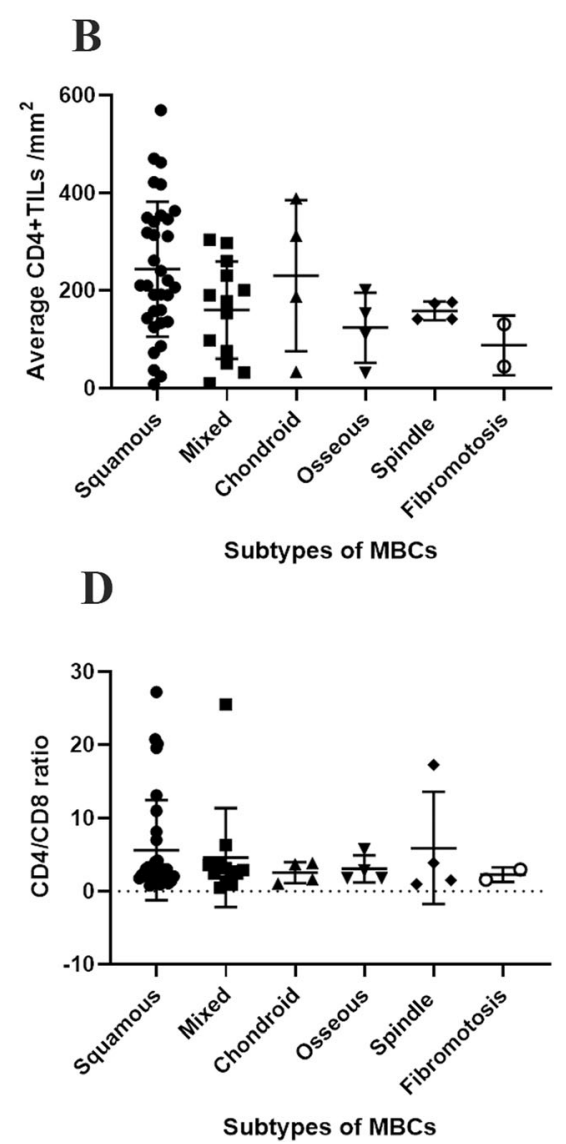

Fig. 3 The stromal TILs counts in different MBC subtypes (a). The squamous cell carcinoma MBCs were more likely to have $>300 / \mathrm{mm}^{2}$ TILS $(p=0.043)$; CD4+ TILs counts in different MBC subtypes (b); CD8+ TILs counts in different MBC subtypes (c) and CD4/CD8 ratio in different MBC subtypes. The asterisk in the figure refers to $p<0.05$ 

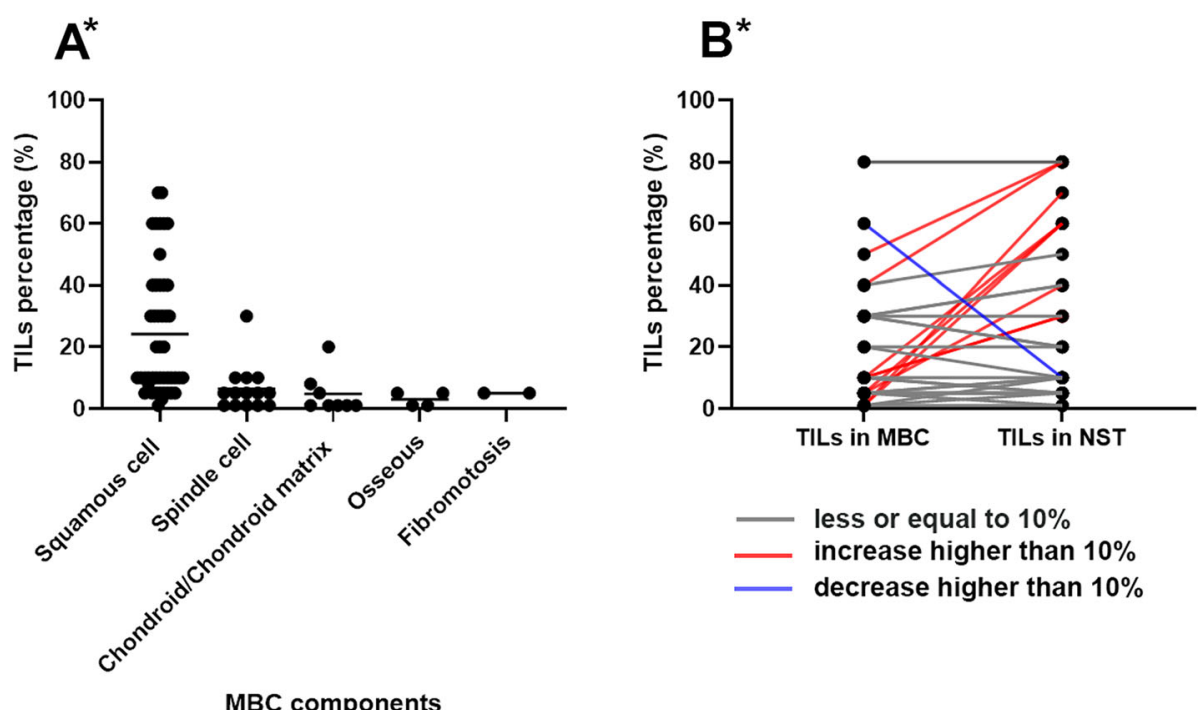

Fig. 4 a The stromal TILs percentage in different MBC components. $\mathbf{b}$ Change of TILs between MBC components and accompanied invasive ductal carcinoma of no special type. Of all the 33 cases, increase in 9, no change in 23, and decrease in 1. TILs, tumor-infiltrating lymphocytes; MBC, metaplastic breast cancer; NST, no special type. The asterisk in the figure refers to $p<0.05$

PDL1 expression in both tumor cells and TILs (Table 2). Twenty-two patients had both greater number of CD8+ TILs $\left(>70 / \mathrm{mm}^{2}\right)$ and positive PDL1 expression tumor cells.

\section{Univariate and multivariate analysis}

We further evaluated the prognostic values of these immune parameters. There is a median follow-up of 48 months (range, 22-163 months).

More TILs (cut-off $\geq 300 / \mathrm{mm}^{2}$ ) in patients with MBC showed a trend for better prognosis ( $\mathrm{HR}, 0.26$; $95 \% \mathrm{CI}$, $0.07-0.97 ; p=0.045$ ), and this trend become stronger in $\mathrm{MBC}$ with squamous cell cancer $(\mathrm{HR}, 0.07 ; 95 \% \mathrm{CI}$, $0.008-0.64 ; p=0.018)$. Also, higher expression of CD4+ (cut-off $\geq 250 / \mathrm{mm}^{2}$ ) and CD8+ (cut-off $\geq 70 / \mathrm{mm}^{2}$ ) TILs keep this trend (CD4: HR, 0.12; 95\%CI, 0.02-0.93; $p=$
0.042; CD8: HR, 0.21; 95\%CI, 0.05-0.95; $p=0.042$ ). Higher number of CD68-positive cells $\left(>300 / \mathrm{m}^{2}\right)$ did not correlate with the patient's outcome (HR 0.74, 95\%CI $0.25-2.21$ ). All the cut-off above was median of the data. The CD4/CD8 ratio had no correlation with DFS (HR, 0.95; 95\%CI, 0.86-1.04; $p=27$ ). Positive PDL1 expression in tumor cells $(\mathrm{HR}, 0.19$; $95 \% \mathrm{CI}, 0.04-0.85$; $p=0.03$ ) and PD1 expression in stromal TILs (HR, 0.20; 95\%CI, $0.05-0.91 ; p=0.04$ ) also predicted a longer DFS. The presence of TLS in tumor predicted better prognoses as well (HR, 0.2; 95\%CI, 0.05-0.75; $p=0.014)$ (Fig. 5),

In addition to the immune parameters described above, the lymphovascular invasion was also found to be significantly associated with shorter DFS (HR, 3.97; 95\%CI, 1.19-13.23; $p=0.03$ ). MBC histological subtypes,

Table 2 Relationship of PDL1 PD1 expression in tumors and stromal TILs with other immune parameters by (non-parametric) Spearman's rank correlation

\begin{tabular}{|c|c|c|c|c|}
\hline & PDL1 in tumor & PDL1 in stromal & PD1 in tumor & PD1 in stromal \\
\hline TILs $\left(>300 / \mathrm{mm}^{2}\right)$ & Rho 0.131 & Rho 0.193 & Rho 0.118 & Rho 0.12 \\
\hline$p$ & 0.33 & 0.17 & 0.38 & 0.38 \\
\hline CD4 + TILs $\left(>250 / \mathrm{mm}^{2}\right)$ & Rho 0.149 & Rho 0.094 & Rho 0.178 & Rho 0.125 \\
\hline$p$ & 0.26 & 0.51 & 0.18 & 0.36 \\
\hline CD8+ TILs $\left(>70 / \mathrm{mm}^{2}\right)$ & Rho 0.492 & Rho 0.367 & Rho -0.018 & Rho 0.128 \\
\hline$p$ & $<0.001$ & 0.006 & 0.89 & 0.34 \\
\hline CD68+ TILs (> 300/mm²) & Rho 0.1 & Rho -0.053 & Rho 0.018 & Rho 0.015 \\
\hline$p$ & 0.45 & 0.71 & 0.89 & 0.91 \\
\hline TILs percentage (> 20\%) & Rho -0.034 & Rho 0 & Rho -0.016 & Rho -0.165 \\
\hline$p$ & 0.80 & 1 & 0.42 & 0.22 \\
\hline
\end{tabular}




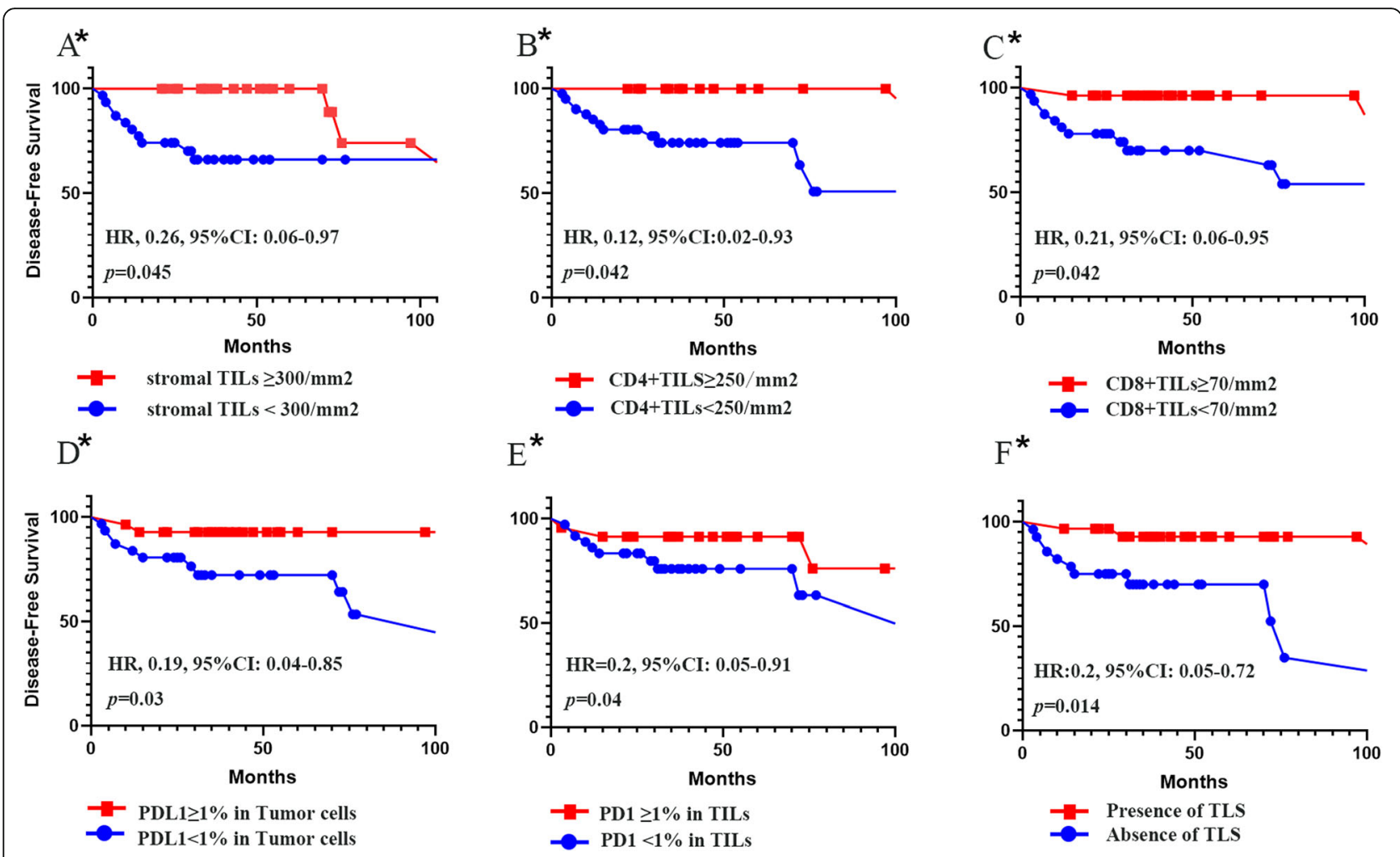

Fig. 5 The prognostic values of immune parameters in MBC. a Stromal TILs. b CD4+ Stromal TILS. c CD8+ Stromal TILs. d PDL1 expression in tumor cells. e PD1 expression in stromal TILs. f Present of TLS in tumor. TILs, tumor-infiltrating lymphocytes; MBC, metaplastic breast cancer; TLS, tertiary lymphoid structure. The asterisk in the figure refers to $p<0.05$

age, tumor size, lymph node status, and surgical type were not associated with DFS.

In multivariate analyses, only stromal TIL was identified as an independent indicator for DFS (HR, 0.17; 95\%CI, 0.04-0.79; $p=0.02$ ) (Table 3).

\section{Discussion}

$\mathrm{MBC}$ is a rare subtype of TNBC with poor prognosis and usually not sensitive to conventional adjuvant therapy. Thus immune therapy may be a promising way to improve the outcome of $\mathrm{MBC}$. In this study, we investigated $60 \mathrm{MBC}$ samples for immune parameters associated with survival, searching for possible prognostic factors and treatment strategies.

MBC exhibited various histological features from epithelia to mesenchyme. Previous studies using wholeexome sequencing found that different components in MBC share identical somatic alterations [23]. Though different components of $\mathrm{MBC}$ shares the same origin, the immune characteristics vary a lot. To our knowledge, this is the first large study focusing on the different components of $\mathrm{MBC}$ to assess their immune microenvironment. We have observed that squamous cell MBCs were more likely to have $>300 / \mathrm{mm}^{2}$ TILs compared to other subtypes $(p=0.043)$. Also, squamous cell component displays the most TILs compared with other components $(p<0.001)$. For the 33 MBCs with IDC-NST, the average percentage of TILs in MBC components was lower in the MBC components compared with NST components. These results indicate that more epithelial differentiation, more TILs.

TILs are basic parameters reflecting the immune status of the tumor. The higher the expression of TILs has been associated with better survival in TNBC and HER-2 positive breast cancer, in both research and clinical practice. In $\mathrm{MBC}$, more TILs were also proved to be correlated with longer DFS (HR, 0.26; 95\%CI, 0.07-0.97; $p=0.045$ ). The most of TILs are cytotoxic CD8+ T cells and CD4+ helper T cells. Both of these two groups play major parts in antitumor immunity [24]. CD8+ T cells can directly kill tumor cells. We found that more CD8+ TILs in MBC predicts better prognosis in MBC (HR, 0.21; 95\%CI, 0.05-0.95; $p=0.042$ ), which resonates with the findings of a previous study involving 1334 patients of all subtypes of breast cancer [25]. While another study found that the CD4+ TILs were independent prognostic factors in hormone negative breast cancer, no correlation was found between CD8+ TILs and clinical outcome [26]. Findings from 
Table 3 Univariate and multivariate cox regression disease-free survival

\begin{tabular}{|c|c|c|c|c|}
\hline \multirow[t]{2}{*}{ Parameters } & \multicolumn{2}{|l|}{ Univariate analysis } & \multicolumn{2}{|l|}{ Multivariate analysis } \\
\hline & $\mathrm{HR}(95 \% \mathrm{Cl})$ & $p$ & HR $(95 \% \mathrm{Cl})$ & $p$ \\
\hline Age $<50$ vs $\geq 50$ & $0.81(0.27-2.41)$ & 0.70 & - & - \\
\hline \multicolumn{5}{|l|}{ Tumor size } \\
\hline $0-20$ & 1 & & - & - \\
\hline $21-50$ & $1.03(0.12-8.99)$ & 0.98 & & \\
\hline$>50$ & $3.73(0.74-32.06)$ & 0.23 & & \\
\hline \multicolumn{5}{|l|}{ Lymph node status } \\
\hline Positive vs negative & $0.92(0.28-2.96)$ & 0.88 & - & - \\
\hline \multicolumn{5}{|l|}{ Lymphvascular invasion } \\
\hline Present vs absent & $3.97(1.19-13.23)$ & 0.03 & $3.52(0.89-13.89)$ & 0.07 \\
\hline With invasive ductal carcinoma (NST) & $0.98(0.33-2.98)$ & 0.97 & - & - \\
\hline \multicolumn{5}{|l|}{ Surgery type } \\
\hline BCS vs mastecomy & $1.07(0.13-8.71)$ & 0.95 & - & - \\
\hline \multicolumn{5}{|l|}{ Histological subtype } \\
\hline Squamous cell & 1 & 0.58 & & \\
\hline Spindle cell & $2.20(0.25-19.50)$ & & & \\
\hline Chondriod & $1.36(0.16-11.68)$ & & & \\
\hline Osseous & $4.44(0.84-23.49)$ & & & \\
\hline Fibromatosis-like & $5.34(0.61-47.10)$ & & & \\
\hline Mixed type & $1.31(0.31-5.49)$ & & & \\
\hline Without/with NST & $1.05(0.35-3.14)$ & 0.93 & & \\
\hline \multicolumn{5}{|l|}{ Stromal TILs $\left(/ \mathrm{mm}^{2}\right)$} \\
\hline$\geq 300$ vs $<300$ & $0.26(0.07-0.97)$ & 0.045 & $0.17(0.04-0.79)$ & 0.024 \\
\hline \multicolumn{5}{|l|}{ CD4+ TILs $\left(/ \mathrm{mm}^{2}\right)$} \\
\hline$\geq 250$ vs $<250$ & $0.12(0.02-0.93)$ & 0.042 & $0.99(0.04-22.43)$ & 0.99 \\
\hline \multicolumn{5}{|l|}{ CD8+ TILs $\left(/ \mathrm{mm}^{2}\right)$} \\
\hline$\geq 70$ vs $<70$ & $0.21(0.05-0.95)$ & 0.042 & $0.56(0.11-2.94)$ & 0.49 \\
\hline \multicolumn{5}{|l|}{ Tumoral PDL1 } \\
\hline Positive vs negative & $0.19(0.04-0.85)$ & 0.03 & $0.39(0.08-2.03)$ & 0.26 \\
\hline \multicolumn{5}{|l|}{ Stromal PD1 } \\
\hline Positive vs negative & $0.20(0.05-0.91)$ & 0.04 & $1.32(0.26-6.87)$ & 0.74 \\
\hline \multicolumn{5}{|l|}{ TLS } \\
\hline Present vs absent & $0.2(0.05-0.75)$ & 0.014 & $0.61(0.15-2.59)$ & 0.51 \\
\hline TMIT* vs others & $0.02(0.01-2.53)$ & 0.116 & & \\
\hline
\end{tabular}

NST, with invasive carcinoma (no special type)

*TMIT tumor microenviroment type refers to the higher CD8+ TILs and positive PDL1 expression of tumor cells

the present study showed that CD4+ TILs correlated with better survival (HR, 0.12; 95\%CI, 0.02-0.93; $p=$ 0.042) as well as CD8+ TILs in MBC. TLSs are ectopic lymph node-like structures characterized by lymphoid aggregation with high endothelial venules. TLSs are induced in a chronic inflammatory environment and their presence is associated with the exacerbation of local immune responses [27]. Here, we found that the presence of TLS was associated with longer survival in $\mathrm{MBC}(\mathrm{HR}, 0.2$; 95\% CI, 0.05-0.75; $p=0.014)$, as well as which were found in TNBC [28].

The expression of PDL1 in breast cancer has a controversial role in predicting prognosis of breast cancer. In the present study, the PDL1 expression in the tumor of MBC appeared in 50\% (36/60) of all the patients, which is similar to the previously reported rate of $20 \%-58.5 \%$ in TNBC $[14,29,30]$. Our data suggested that PDL1 expression correlated with better survival (HR, 0.19; $95 \% \mathrm{CI}, \quad 0.04-0.85 ; \quad p=0.03)$ in $\mathrm{MBC}$, which was 
consistent with some previous studies [31, 32] but contradicted with that of a meta-analysis involving 9 studies [33]. Different PDL1 immunohistochemistry assays, various scoring systems, and evaluation of different tumor compartments may be the reasons for this observed diversity [34]. Thus, a prospective study correlated with the treatment effect of PDL1/PD1 blockade is awaited to define the proper PDL1 expression assay.

The performance of different clones in PDL1 detection differs in breast cancer. PDL1 (E1L3N) identified more PD-L1-positive cases (14.7\%, cut-off $1 \%$ ) compared with SP142 (11.5\%) and 28-8 (13.3\%) in triple-negative breast cancer [35]. Adams et.al used PDL1 (E1L3N) detecting $62(48.75 \%)$ positive expression on tumor cells (cut-off $10 \%)$ in triple-negative breast cancer [36]. A metaanalysis of 38 studies revealed clone 28-8 yielding the highest positive rate (39\%) on tumor cells in all breast cancer with different thresholds in all studies [37]. Data from IMpassion130 study using SP142 identified 369 (40.9\%) PD-L1-positive expression on immune cells [38]. Our study used PDL1(E1L3N) identified $30(50 \%)$ positive expression on tumor cells and 36 (60\%) positive expression on immune cells, which may identify more PDL1-positive tumors.

TILs infiltration pattern in MBC with mesenchymal elements differs from carcinoma due to the histological characteristics. The TILs infiltrated diffusely in the mesenchymal elements. The distribution of $\mathrm{CD} 4+$ and CD8+ TILs also follows this trend. Previous studies involved TILs and its subtypes also correlated with survival in soft tissue sarcoma [39-41]. A study involved 47 leiomyosarcomas revealed an average number of 10.5 CD4+ TILs and 16.1 CD8+ TILs per high power filed (CD4 $33.87 / \mathrm{mm}^{2}$, CD8 $51.93 / \mathrm{mm}^{2}$ ) [42], which is lower than the average number in $\mathrm{MBC}$ with mesenchymal elements (CD4 209.99 $\pm 140.10 / \mathrm{mm}^{2}$, CD8 83.34 \pm 78.09 / $\mathrm{mm}^{2}$ ). Further, no significant difference in TILs was found among different mesenchymal subtypes $(p=0.30)$. Another study revealed different PDL1 expression in various sarcoma [43]. Overall, 6/14 MBC with mesenchymal elements had positive PDL1 expression, no significant difference was observed among mesenchymal subtypes $(p=0.83)$.

MBC displays aggressive biological behavior, which is not sensitive to adjuvant therapy. Thus, immune checkpoints therapy may be a promising treatment for MBC. Previous clinical trials demonstrated that patients with PDL1-positive cells and increased TILs have better response to immune therapy $[15,44]$. The selection of proper patients for immune therapy is largely based on the expression of PDL1/PD1 and density of TILs. We also found that both of the PDL1 expression in tumor cells (rho 0.492, $p<0.001$ ) and stromal TILs (rho 0.367, $p=0.006)$ had a strong correlation with CD8+ TILs number. And these results were as expected that CD8+ $\mathrm{T}$ cells may be more sensitive to modulation of PDL1/ PD1 pathway [45]. Tumors with a greater number of CD8+ TILs and positive PDL1 expression tumor cells were identified as tumor microenvironment type (TMIT) 1 according to the previous study [46]. Twenty-two patients were identified as TMIT 1 in our study, who can benefit from anti-PDL1-PD1 therapy. Our results suggest that the combination of these immune parameters may help to improve MBC patient selections for immune therapy. Further, a study indicated the relationship between PDL1 expression and macrophages (CD68 positive) [47], while we did not observe the tendency in MBC.

In this study, we have evaluated the TILs and immune checkpoints parameters expression in different components of MBC. The percentage of TILs as well as counts of TILs was both studied. These immune parameters have also been proved to be correlated with survival in MBC. However, we still have some limitations in this study. The sample size was limited due to the low incidence of MBC. Although the immune characteristics of $\mathrm{MBC}$ are similar with those observed in triple-negative breast cancer, it needs to be further validated in other data sets. Also, the detection of PDL1 expression was not correlated with treatment effect. The antibody $($ E1L3N) we used for PDL1 detection has been used and proved to have the highest positive rate in triplenegative breast cancer [35, 48]; it was not correlated with any PDL1/PD1 blockade drugs now and maybe overestimating PD-L1-positive tumors compared with FDA approved PDL1(SP142).

\section{Conclusions}

We have demonstrated the immune characteristics of different subtypes in MBC. TILs, CD4+ TILs, CD8+ TILs, and the presence of TLS were found to be correlated with better prognosis in MBC. The expression of PDL1 in tumor cells was also found to be correlated with CD8+ TILs and associated with longer survival. These data suggested that immune checkpoint therapy may be a promising treatment in a certain type of MBC.

\section{Supplementary information}

Supplementary information accompanies this paper at https://doi.org/10. 1186/s13058-020-01330-6.

Additional file 1: Supplemental Figure 1. Representative images of the tertiary lymphoid structures stained with CD3/CD20 (CD3 = T cells, brown; CD20 = B cells, red).

Additional file 2: Supplemental Figure 2. Representative tissue section of a mixed type MBC (squamous cell cancer component and chondroid-matrix component, the same case in Fig. 2) with CD68 stains (original magnification $\times 200$ ). 
Additional file 3: Supplemental Figure 3. CD68+ TILs counts in different subtypes of MBC.

Additional file 4: Supplemental Table 1. Pathological characteristics of 33 cases with invasive carcinoma of no special type. Supplemental Table 2. The correlation of PDL1 expression in both tumor and stromal cells. Supplemental Table 3. The correlation of PD1 expression in both tumor and stromal cells. Supplemental Table 4. The PDL1 and PD1 expression in both tumor and stromal cells shares no difference in all subtypes of the MBCs.

\section{Acknowledgments}

We thank all the patients who participated in this study and for their willingness to contribute their data.

\section{Authors' contributions}

CX participated in the interpretation and analysis of data and drafted the manuscript. LLL and SP participated in the interpretation of the data. YX carried out the experiments. LM, LRZ, HYH, and HJH participated in the acquisition and interpretation of pathologic data. YJP conceived of the study, participated in its design, and edited the manuscript. The authors read and approved the final manuscript.

\section{Funding}

This work was supported by grants from the Natural Science Foundation of China (81702759).

\section{Availability of data and materials}

The authenticity of this article has been validated by uploading the key raw data onto the Research Data Deposit public platform (www.researchdata.org. cn), with the approval RDD number as RDDA2020001424

\section{Ethics approval and consent to participate}

The study was approved by the ethics committee of the Sun Yat-sen University Cancer Center. All patients were systemically asked for consent to use their data anonymously for analysis and publication.

\section{Consent for publication}

Not applicable.

\section{Competing interests}

There are no known conflicts of interest associated with this publication and there has been no significant financial support for this work that could have influenced its outcome.

\section{Received: 9 April 2020 Accepted: 11 August 2020}

Published online: 18 August 2020

\section{References}

1. Pezzi CM, Patel-Parekh L, Cole K, Franko J, Klimberg VS, Bland K. Characteristics and treatment of metaplastic breast cancer: analysis of 892 cases from the National Cancer Data Base. Ann Surg Oncol. 2007; 14(1):166-73.

2. Rayson D, Adjei AA, Suman VJ, Wold LE, Ingle JN. Metaplastic breast cancer: prognosis and response to systemic therapy. Ann Oncol. 1999;10(4):413-9.

3. Al-Hilli Z, Choong G, Keeney MG, Visscher DW, Ingle JN, Goetz MP, et al. Metaplastic breast cancer has a poor response to neoadjuvant systemic therapy. Breast Cancer Res Treat. 2019;176(3):709-16.

4. Lai HW, Tseng LM, Chang TW, Kuo YL, Hsieh CM, Chen ST, et al. The prognostic significance of metaplastic carcinoma of the breast (MCB)--a case controlled comparison study with infiltrating ductal carcinoma. Breast. 2013;22(5):968-73.

5. Nelson RA, Guye ML, Luu T, Lai LL. Survival outcomes of metaplastic breast cancer patients: results from a US population-based analysis. Ann Surg Oncol. 2015;22(1):24-31.

6. El Zein D, Hughes $M$, Kumar S, Peng X, Oyasiji T, Jabbour $H$, et al. Metaplastic carcinoma of the breast is more aggressive than triple-negative breast cancer: a study from a single institution and review of literature. Clin Breast Cancer. 2017;17(5):382-91.

7. Adams S, Gray RJ, Demaria S, Goldstein L, Perez EA, Shulman LN, et al. Prognostic value of tumor-infiltrating lymphocytes in triple-negative breast cancers from two phase III randomized adjuvant breast cancer trials: ECOG 2197 and ECOG 1199. J Clin Oncol. 2014;32(27):2959-66.

8. Loi S, Michiels S, Salgado R, Sirtaine N, Jose V, Fumagalli D, et al. Tumor infiltrating lymphocytes are prognostic in triple negative breast cancer and predictive for trastuzumab benefit in early breast cancer: results from the FinHER trial. Ann Oncol. 2014;25(8):1544-50.

9. Loi S, Sirtaine N, Piette F, Salgado R, Viale G, Van Eenoo F, et al. Prognostic and predictive value of tumor-infiltrating lymphocytes in a phase III randomized adjuvant breast cancer trial in node-positive breast cancer comparing the addition of docetaxel to doxorubicin with doxorubicinbased chemotherapy: BIG 02-98. J Clin Oncol. 2013;31(7):860-7.

10. Matsumoto H, Thike AA, Li H, Yeong J, Koo SL, Dent RA, et al. Increased CD4 and CD8-positive T cell infiltrate signifies good prognosis in a subset of triple-negative breast cancer. Breast Cancer Res Treat. 2016;156(2):237-47.

11. Wang K, Shen T, Siegal GP, Wei S. The CD4/CD8 ratio of tumor-infiltrating lymphocytes at the tumor-host interface has prognostic value in triplenegative breast cancer. Hum Pathol. 2017;69:110-7.

12. Baptista MZ, Sarian LO, Derchain SF, Pinto GA, Vassallo J. Prognostic significance of PD-L1 and PD-L2 in breast cancer. Hum Pathol. 2016:47(1): 78-84.

13. Yan $\mathrm{L}$, Zhang $\mathrm{W}$. Precision medicine becomes reality-tumor type-agnostic therapy. Cancer Commun (Lond). 2018;38(1):6.

14. Muenst S, Schaerli AR, Gao F, Daster S, Trella E, Droeser RA, et al. Expression of programmed death ligand 1 (PD-L 1) is associated with poor prognosis in human breast cancer. Breast Cancer Res Treat. 2014;146(1):15-24.

15. Schmid P, Adams S, Rugo HS, Schneeweiss A, Barrios $\mathrm{CH}$, Iwata $\mathrm{H}$, et al. Atezolizumab and nab-paclitaxel in advanced triple-negative breast cancer. N Engl J Med. 2018;379(22):2108-21.

16. Emens LA, Cruz C, Eder JP, Braiteh F, Chung C, Tolaney SM, et al. Long-term clinical outcomes and biomarker analyses of atezolizumab therapy for patients with metastatic triple-negative breast cancer: a phase 1 study. JAMA Oncol. 2019:5(1):74-82.

17. Noske A, Mobus V, Weber K, Schmatloch S, Weichert W, Kohne CH, et al. Relevance of tumour-infiltrating lymphocytes, PD-1 and PD-L1 in patients with high-risk, nodal-metastasised breast cancer of the German Adjuvant Intergroup Node-positive study. Eur J Cancer. 2019:114:76-88.

18. Lakhani SR, Ellis IO, Schnitt, SJ, Tan PH, van de Vijver MJ. World Health Organization classification of tumours of the breast. World Health Organization Classification of Tumours. 2012;4:48-52.

19. Hendry S, Salgado R, Gevaert T, Russell PA, John T, Thapa B, et al. assessing tumor-infiltrating lymphocytes in solid tumors: a practical review for pathologists and proposal for a standardized method from the International Immuno-Oncology Biomarkers Working Group: Part 2: TILs in melanoma, gastrointestinal tract carcinomas, non-small cell lung carcinoma and mesothelioma, endometrial and ovarian carcinomas, squamous cell carcinoma of the head and neck, genitourinary carcinomas, and primary brain tumors. Adv Anat Pathol. 2017:24(6):311-35.

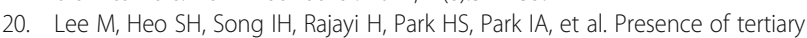
lymphoid structures determines the level of tumor-infiltrating lymphocytes in primary breast cancer and metastasis. Mod Pathol. 2019;32(1):70-80.

21. Buisseret L, Desmedt C, Garaud S, Fornili M, Wang X, Van den Eyden G, et al. Reliability of tumor-infiltrating lymphocyte and tertiary lymphoid structure assessment in human breast cancer. Mod Pathol. 2017;30(9): 1204-12.

22. Qin T, Zeng YD, Qin G, Xu F, Lu JB, Fang WF, et al. High PD-L1 expression was associated with poor prognosis in 870 Chinese patients with breast cancer. Oncotarget. 2015;6(32):33972-81.

23. Avigdor BE, Beierl K, Gocke CD, Zabransky DJ, Cravero K, Kyker-Snowman K, et al. Whole-exome sequencing of metaplastic breast carcinoma indicates monoclonality with associated ductal carcinoma component. Clin Cancer Res. 2017;23(16):4875-84

24. Bense RD, Sotiriou C, Piccart-Gebhart MJ, Haanen J, van Vugt M, de Vries $E G E$, et al. Relevance of tumor-infiltrating immune cell composition and functionality for disease outcome in breast cancer. J Natl Cancer Inst. 2017; 109(1):djw192. https://doi.org/10.1093/jnci/djw192. Print 2017 Jan.

25. Mahmoud SM, Paish EC, Powe DG, Macmillan RD, Grainge MJ, Lee AH, et al. Tumor-infiltrating CD8+ lymphocytes predict clinical outcome in breast cancer. J Clin Oncol. 2011:29(15):1949-55.

26. Chung YR, Kim HJ, Jang MH, Park SY. Prognostic value of tumor infiltrating lymphocyte subsets in breast cancer depends on hormone receptor status. Breast Cancer Res Treat. 2017;161(3):409-20. 
27. Goc J, Fridman WH, Sautes-Fridman C, Dieu-Nosjean MC. Characteristics of tertiary lymphoid structures in primary cancers. Oncoimmunology. 2013; 2(12):e26836.

28. Lee HJ, Park IA, Song IH, Shin SJ, Kim JY, Yu JH, et al. Tertiary lymphoid structures: prognostic significance and relationship with tumour-infiltrating lymphocytes in triple-negative breast cancer. J Clin Pathol. 2016;69(5):422-30.

29. Mittendorf EA, Philips AV, Meric-Bernstam F, Qiao N, Wu Y, Harrington S, et al. PD-L1 expression in triple-negative breast cancer. Cancer Immunol Res. 2014;2(4):361-70.

30. Nanda R, Chow LQ, Dees EC, Berger R, Gupta S, Geva R, et al. Pembrolizumab in patients with advanced triple-negative breast cancer: phase Ib KEYNOTE-012 study. J Clin Oncol. 2016;34(21):2460-7.

31. Beckers RK, Selinger Cl, Vilain R, Madore J, Wilmott JS, Harvey K, et al. Programmed death ligand 1 expression in triple-negative breast cancer is associated with tumour-infiltrating lymphocytes and improved outcome. Histopathology. 2016;69(1):25-34.

32. Uhercik M, Sanders AJ, Owen S, Davies EL, Sharma AK, Jiang WG, et al. Clinical significance of PD1 and PDL1 in human breast cancer. Anticancer Res. 2017;37(8):4249-54.

33. Wang C, Zhu H, Zhou Y, Mao F, Lin Y, Pan B, et al. Prognostic value of PDL1 in breast cancer: a meta-analysis. Breast J. 2017;23(4):436-43.

34. Wang J, Xi J, Zhang H, Li J, Xia Y, Xi R, et al. Somatic mutations in renal cell carcinomas from Chinese patients revealed by targeted gene panel sequencing and their associations with prognosis and PD-L1 expression. Cancer Commun (Lond). 2019;39(1):37.

35. Sun WY, Lee YK, Koo JS. Expression of PD-L1 in triple-negative breast cancer based on different immunohistochemical antibodies. J Transl Med. 2016; 14(1):173.

36. Adams TA, Vail PJ, Ruiz A, Mollaee M, McCue PA, Knudsen ES, et al. Composite analysis of immunological and metabolic markers defines novel subtypes of triple negative breast cancer. Mod Pathol. 2018;31(2): 288-98.

37. Matikas A, Zerdes I, Lovrot J, Richard F, Sotiriou C, Bergh J, et al. Prognostic implications of PD-L1 expression in breast cancer: systematic review and meta-analysis of immunohistochemistry and pooled analysis of transcriptomic data. Clin Cancer Res. 2019;25(18):5717-26.

38. Schmid P, Rugo HS, Adams S, Schneeweiss A, Barrios CH, Iwata H, et al. Atezolizumab plus nab-paclitaxel as first-line treatment for unresectable, locally advanced or metastatic triple-negative breast cancer (IMpassion130): updated efficacy results from a randomised, double-blind, placebocontrolled, phase 3 trial. Lancet Oncol. 2020;21(1):44-59.

39. Fujii $H$, Arakawa A, Utsumi D, Sumiyoshi S, Yamamoto $Y$, Kitoh A, et al. CD8(+) tumor-infiltrating lymphocytes at primary sites as a possible prognostic factor of cutaneous angiosarcoma. Int J Cancer. 2014;134(10): 2393-402.

40. Liu P, Xiao Q, Zhou B, Dai Z, Kang Y. Prognostic significance of programmed death ligand 1 expression and tumor-infiltrating lymphocytes in axial osteosarcoma. World Neurosurg. 2019;129:e240-e54.

41. Feng Y, Shen J, Gao Y, Liao Y, Cote G, Choy E, et al. Expression of programmed cell death ligand 1 (PD-L1) and prevalence of tumorinfiltrating lymphocytes (TILs) in chordoma. Oncotarget. 2015;6(13): 11139-49.

42. Lee ATJ, Chew W, Wilding CP, Guljar N, Smith MJ, Strauss DC, et al. The adequacy of tissue microarrays in the assessment of inter- and intratumoural heterogeneity of infiltrating lymphocyte burden in leiomyosarcoma. Sci Rep. 2019;9(1):14602.

43. Pollack SM, He Q, Yearley JH, Emerson R, Vignali M, Zhang Y, et al. T-cell infiltration and clonality correlate with programmed cell death protein 1 and programmed death-ligand 1 expression in patients with soft tissue sarcomas. Cancer. 2017;123(17):3291-304.

44. Adams S, Schmid P, Rugo HS, Winer EP, Loirat D, Awada A, et al. Pembrolizumab monotherapy for previously treated metastatic triplenegative breast cancer: cohort a of the phase II KEYNOTE-086 study. Ann Oncol. 2019;30(3):397-404

45. Carter L, Fouser LA, Jussif J, Fitz L, Deng B, Wood CR, et al. PD-1:PD-L inhibitory pathway affects both CD4(+) and CD8(+) T cells and is overcome by IL-2. Eur J Immunol. 2002;32(3):634-43.

46. Ock CY, Keam B, Kim S, Lee JS, Kim M, Kim TM, et al. Pan-cancer immunogenomic perspective on the tumor microenvironment based on PD-L1 and CD8 T-cell infiltration. Clin Cancer Res. 2016;22(9):226170.
47. Liu Y, Zugazagoitia J, Ahmed FS, Henick BS, Gettinger SN, Herbst RS, et al. Immune cell PD-L1 colocalizes with macrophages and is associated with outcome in PD-1 pathway blockade therapy. Clin Cancer Res. 2020;26(4): 970-7.

48. Wimberly H, Brown JR, Schalper K, Haack H, Silver MR, Nixon C, et al. PD-L1 expression correlates with tumor-infiltrating lymphocytes and response to neoadjuvant chemotherapy in breast cancer. Cancer Immunol Res. 2015; 3(4):326-32

\section{Publisher's Note}

Springer Nature remains neutral with regard to jurisdictional claims in published maps and institutional affiliations.

\section{Ready to submit your research? Choose BMC and benefit from:}

- fast, convenient online submission

- thorough peer review by experienced researchers in your field

- rapid publication on acceptance

- support for research data, including large and complex data types

- gold Open Access which fosters wider collaboration and increased citations

- maximum visibility for your research: over $100 \mathrm{M}$ website views per year

At BMC, research is always in progress.

Learn more biomedcentral.com/submissions 